\title{
A Study of the Construction of English Hidden Curriculums at Primary Schools in China
}

\author{
Haiwen $\mathrm{Mo}^{1} \&$ Fengjuan Luo ${ }^{1}$ \\ ${ }^{1}$ School of Foreign Studies, Guangdong Lingnan Normal University, Guangdong Province, China \\ Correspondence: Haiwen Mo, School of Foreign Studies, Guangdong Lingnan Normal University, Guangdong \\ Province, China.
}

Received: July 2, 2019 Accepted: August 14, 2019 Online Published: August 16, 2019

doi: 10.5539/elt.v12n9p66 URL: https://doi.org/10.5539/elt.v12n9p66

\begin{abstract}
The hidden curriculum is an important part of curriculums, and constructing the primary school English hidden curriculum is helpful for the implementation of the new National English Curriculums, the development of students' key competencies and the reform of basic English teaching in China. However, according to the survey conducted with 40 primary school leaders, 60 primary school English teachers as well as 300 primary school students, the hidden curriculum is always ignored in primary school English teaching in China. Schools should meticulously design the educational environment on campus, highlighting the characteristics of English hidden curriculums, integrate English into the class culture, optimizing English educational environment. It is necessary to build a harmonious relationship between teachers and students, to enhance students' motivation of learning English, to mobilize social and family participation, and to build multiple hidden curricular resources of English so as to promote the reform of English teaching and improve the quality of English teaching at primary schools in China.
\end{abstract}

Keywords: primary school English; hidden curriculum; English teaching; teaching reform in China

\section{Introduction}

In 2001, the Ministry of Education of China promulgated the new National English Curriculums and declared that all the primary schools should teach English as a compulsory course form Grade three (Ministry of Education of China, 2001). After 10 years of education reform, National English Curriculums for compulsory education was officially promulgated in 2011, which set higher and more specific requirements for English teaching at primary schools (Ministry of Education of China, 2011). Some primary schools begin to teach English form Grade one. In 2014, opinions on comprehensively deepening curriculum reform and implementing the fundamental task of cultivating moral talents were issued by Ministry of Education of China, which required the development of students' core competencies to further deepen the reform of basic education in China. It has been more than ten years since the new round of curriculum reform of basic education. English in China is a foreign language and a compulsory course at the primary schools. According to the data by Ministry of Education of China, there more than 100 million students at primary schools in 2018 in China, but they lack opportunities to use English in their real life and their English communicative competence is far from satisfactory. English teachers are burdened with heavy teaching tasks and many problems in English teaching resources and language learning environment arise. In recent years, the development of English curriculum resources has attracted more and more attention from scholars. In China's basic foreign language education research, most of the previous studies focused on the construction of English explicit curriculum resources, and the research on the construction of implicit curriculum resources was insufficient. Based on the survey and practice of English teaching, this paper explores the problems in English hidden curriculum and puts forward some suggestions on the construction of English hidden curriculum at primary schools under the background of the new curriculum reform, so as to provide reference for relevant research and better promote the smooth development of basic English education reform in China.

\section{Literature Review}

In the 1960s and 1970s, scholars began to pay attention to the study of the hidden curriculum, and Jackson was one of the earliest scholars who made a more systematic study of the hidden curriculum. In his works Life in the classroom. Jackson pointed out that the values and ideologies that students learned in school were not totally 
obtained by formal course teaching; informal cultural acquisition and experiential knowledge were hidden curriculums (Jackson, 1968). As a matter of fact, collateral learning, concomitant learning and associate learning mentioned by Deway at the beginning of last century were the beginning research on the hidden curriculum, referring to the spontaneous attitude, emotion and value in the process of learning. In the 1980s, Chinese scholars began to systematically study the hidden curriculum, and many teachers began to pay more attention to the development of the hidden curriculum in teaching. Zhang Hua pointed out that hidden curriculum was the unanticipated or unplanned knowledge, values, norms and attitudes that students learned in the learning environment, including material environment, social environment, and cultural environment system. Such courses are of course informal, unofficial, potential, and hidden (Zhang, 2000). Although the hidden curriculum is related to the explicit curriculum, in fact, the "curriculum" in the hidden curriculum does not actually refer to the curriculum, but to educational factors that have an unconscious influence on students' development in schools and the society (Ye et al., 2003). Different scholars have different understanding of hidden curriculum, but they all agree that hidden curriculum plays a positive role in the development of students. In fact, the hidden curriculum is not in the traditional sense of the course; it is the implicit social, school, and family factors that influence student's cognitive development.

English is the most important foreign language in China's education system. Compared with other subjects, English has great differences in knowledge structure and teaching methods. As a new main subject, primary school English needs to plan the explicit curriculum and give full play to the active role of the hidden curriculum, so as to effectively improve the efficiency of primary school English teaching. People can easily acquire their mother tongue without systematically studying explicit language knowledge. Social factors of second language acquisition and learners' cognitive mechanism are equally important, and second language acquisition is the result of the interaction between learners, peers, environment and other learning resources (Luo, 2017). It can be seen that environment and other factors have an important impact on language acquisition. Specifically, English hidden curriculum includes campus construction and campus culture, school English teaching management system, school English learning traditions, various extracurricular English learning practice activities and students' unconsciously acquired educational experience and other factors affecting English teaching and learning. From the perspective of English teaching at primary schools, the hidden curriculum is beneficial to the students' English acquisition and cognitive development. The development of English hidden curriculum at primary schools is conducive to consolidating the language knowledge learned by primary students, expanding students' learning horizons, providing a favorable humanistic environment for language teaching, arousing students' interest in English learning, and promoting the reform of English teaching at primary schools. However, the research on English hidden curriculum in China needs a systematic study.

\section{The Significance of Primary School English Hidden Curriculum Construction in China}

\subsection{It Is Conducive to the Implementation of English Curriculum Standards}

With the development of China's economy, English becomes more and more important and has constituted a vital and compulsory course in schools at different stages in China. Reasonable development and active utilization of course resources are important guarantees for effective implementation of English course standards (Ministry of Education of China, 2011: 41). The important task of primary school English curriculum is to stimulate students' interest in English learning, develop their ability to use English, and develop their positive emotional attitudes towards English and its culture. However, in the actual teaching process, many primary school English teachers overemphasize the memorization of knowledge, ignore the creation of situations for students' communication, and consequently fail to improve students' English communicative competence. National English Curriculums in China emphasizes the use of language learning, and advocate that students should learn and use English in a meaningful context. English learning needs adequate comprehensible language input. In addition to the explicit resources of classroom teaching, the rich and varied implicit curriculum resources have a subtle positive effect on students' English acquisition. The English curriculum should be based on the demand of the teaching and learning, and teachers should try to provide the opportunity for students to use English, and make full use of different kinds of English learning resources, such as videos, newspapers, magazines, network information, etc., to promote students' English learning (Ministry of Education of China, 2011: 41). English learning is the process in which students experience the language and culture of English-speaking countries. The construction of the hidden curriculum for English courses at primary schools can help students better understand foreign cultures, deepen their understanding of the language and culture of English-speaking countries, and improve their intercultural communication skills. We should not only set up explicit curriculum and make good use of explicit curriculum resources, but also give full play to the active role 
of hidden curriculum, so as to better implement National English Curriculums and promote the comprehensive development of primary school students.

\subsection{It Is Conducive to the Development of Primary School Students' Core Competencies}

The key competencies of English subject in China can be summarized into four aspects: language competency, cultural competency, thinking competency and learning competency (Cheng \& Zhao, 2016). The development of English hidden curriculum at primary schools is conducive to improving the comprehensive English language ability, developing thinking ability and forming excellent cultural competency. English learning is more dependent on the environment than other subjects. A good English learning environment is significant to language acquisition. The development and utilization of English hidden curriculum at primary schools are essential to creating a more optimized English acquisition environment, enabling students to acquire English language and culture in a more natural environment, forming their own cultural positions and improving their English communicative competence. As a core competency, learning ability not only includes learning methods and strategies but also includes knowledge and attitude towards English learning (Cheng \& Zhao, 2016). For primary school students in China, English is a foreign language constrained by many factors. As a matter of fact, the development of English hidden curriculum is to create a better English acquisition environment for primary school students, promoting the formation of their good English learning habits, making them better at adjusting the learning process with strategies, improving their learning ability, and better developing the key competencies of English subject.

\subsection{It Is Conducive to the Reform of English Teaching}

Promoting the reform of examination and evaluation system, and developing students' key competencies of English subject are the main tasks of the curriculum reform of basic English education in China (Cheng, 2017). However, at the primary schools in China, a lot of English teachers only focus on the teaching of language knowledge, and many students just mechanically memorize the grammatical points and try to get high marks in the test, ignoring the communicative function of language and the educational function of English subject. Many schools hope that English classroom teaching becomes more effective, but ignore the construction of English cultural environment and the improvement of learning atmosphere on campus. English teachers have some scattered ideas and practices on building a good English learning atmosphere, but they are far from meeting the needs of students' development. The development of hidden English curriculum at primary schools and various effective English teaching resources can make up for the deficiency of explicit English curriculum and give better play to the role of English curriculum in the cultivation of students' key competencies. Language teaching should make good use of hidden curriculum, and learner-centered courses should focus on learners' development needs and cognitive development (Nunan, 1989). Therefore, teachers should renew their ideas, give full play to the positive role of the hidden English curriculum, build up English learning atmosphere, promote interactions between students and teachers, reduce students' anxiety in learning English, optimize the English teaching environment, and improve the quality of English teaching. Curriculum innovation is the core task of education reform (Zhong, 2009). The construction of hidden English curriculums at primary schools is of great benefit to the curriculum innovation and English teaching reform in China. With the development of science and technology, hidden curriculum resources are becoming more and more abundant. Under the background of new curriculum reform, the rational development and utilization of multiple hidden curriculum resources are conducive to the in-depth development of primary school English teaching reform in China.

\section{Method}

In order to have a better understanding of the roles and functions of hidden curriculum at primary school English teaching in China, we conducted a survey among primary school leaders, English teachers and students to gain a sense of the participants' views on the construction of English hidden curriculum, perceptions concerning English reforms, as well as to explore future avenues for ongoing primary school teaching research in China.

Participants included 40 primary school leaders in 40 primary schools, 60 primary school English teachers as well as 300 primary school students in Zhanjiang City, Guangdong Province, China. We sent a bilingual (English and Chinese) survey questionnaire to some leaders, teachers, and students. And some open-ended questions were used to interview leaders and teachers to describe their opinions and feelings about English hidden curriculum. All the surveys are conducted on a voluntary basis. The results were used to evaluate participants' opinions about English hidden curriculum and English teaching reform at primary schools.

\section{Results and Discussion}

\subsection{Leaders' Opinions on the Construction of English Hidden Curriculum}


Table 1. Primary school leaders' opinions on the construction of English hidden curriculum

\begin{tabular}{llllll}
\hline $\begin{array}{l}\text { What do you think of the Very important } \\
\text { construction of English hidden } \\
\text { curriculum at primary schools? }\end{array}$ & $\begin{array}{l}\text { for } \begin{array}{l}\text { English } \\
\text { teaching }\end{array} \\
\text { for } \\
\text { teaching }\end{array}$ & $\begin{array}{l}\text { English } \\
\text { for so important } \\
\text { teaching }\end{array}$ & $\begin{array}{l}\text { Not important } \\
\text { for } \\
\text { teaching }\end{array}$ \\
\hline Percentage & 0 & $5 \%$ & $5 \%$ & $90 \%$ \\
\hline
\end{tabular}

According to the survey, only two of the forty primary school leaders agreed that the construction of English hidden curriculum was fairly important for English teaching, and 90\% neglect its importance for primary school English teaching. In the interview, most of the leaders held that the examinations are good ways to improve students' scores even they realized the significance of English communicative ability; two school leaders insisted that their schools pay much more attention to the construction and implementation of hidden curriculum, and the arrangement of English second class activities is relatively systematic. These two schools greatly valued the importance of English hidden curriculum, which is attributed to the fact that the school's main leaders are English teachers, and other schools lack planning for the development of English hidden curriculum.

In China, many primary schools only focus on the examination and memorization of English knowledge but neglect the application of language knowledge. Insufficient attention was paid to the development and utilization of English hidden curriculum. The English hidden curriculum of primary school is still in a state of disorder, scattered and unsystematic. The lack of English hidden curriculum in schools and the failure to carry out all kinds of activities of the hidden curriculum in a planned way are not beneficial to the development of pupils' ability to use English and cross-cultural awareness.

\subsection{Teachers' Opinions on the Cultivation of English Hidden Curriculums}

Table 2. Primary school teachers' opinions on the cultivation of English hidden curriculum

\begin{tabular}{lll}
\hline $\begin{array}{l}\text { I feel interested in the cultivation of the hidden } \\
\text { curriculum and often organize the English }\end{array}$ & strongly disagree & $66.7 \%$ \\
extracurricular activities. & disagree & $16.7 \%$ \\
& agree or disagree & $8.3 \%$ \\
& agree & $6.7 \%$ \\
& strongly agree & $1.6 \%$ \\
\cline { 1 - 2 } $\begin{array}{l}\text { I would like to cultivate English hidden } \\
\text { curriculum, but do not have the professional }\end{array}$ & strongly disagree & $3.3 \%$ \\
$\begin{array}{l}\text { quality to carry out various hidden curriculum } \\
\text { activities. }\end{array}$ & disagree & $13.3 \%$ \\
& agree or disagree & $16.7 \%$ \\
& agree & $30 \%$ \\
I am not interested in the cultivation of hidden & strongly agree & $36.7 \%$ \\
curriculum and do not have time. & strongly disagree & $3.3 \%$ \\
& disagree & $8.3 \%$ \\
& agree or disagree & $16.7 \%$ \\
& agree & $30 \%$ \\
\hline
\end{tabular}

According to the investigation, less than $10 \%$ of the teachers often organize English extracurricular activities; $66.7 \%$ of the teachers think that they do not have the professional quality and knowledge to carry out various hidden curriculum activities; $71.7 \%$ of the teachers complained that they do not have interest and time to cultivate hidden curriculum resources. In the interview, most of the primary school English teachers think that they are worn out with the normal teaching tasks (explicit classroom teaching), and lack time to carry out English hidden curriculum; and many teachers hold that they do not have the corresponding ability to organize English extracurricular activities, and lack the confidence to guide the students in various hidden curriculum activities. We can easily see that one of the main reasons why many schools fail to develop and utilize English 
hidden curriculum is that teachers lack initiative and cannot effectively guide students to carry out relevant English activities. In primary school English teaching, teachers should provide opportunities for primary school students to participate in various forms of hidden curriculum activities to experience and use English, so that they can better understand and acquire English. Due to the lack of initiative and comprehensive quality of English teachers, the construction of English hidden curriculum at primary schools is problematic.

\subsection{Students' Opinions on English Hidden Curriculum}

Table 3. Primary school students' opinions on English hidden curriculum

\begin{tabular}{lll}
\hline I like English extracurricular activities. & strongly disagree & $3.7 \%$ \\
& disagree & $4.3 \%$ \\
& agree or disagree & $5.3 \%$ \\
& agree & $15 \%$ \\
Our school often carries out various English & strongly agree & $71.7 \%$ \\
extracurricular activities. & strongly disagree & $71.7 \%$ \\
& disagree & $13.7 \%$ \\
I am able to learn a lot in various English & agree or disagree & $7.3 \%$ \\
extracurricular activities. & strongly disagree & $4.3 \%$ \\
& agree & $3 \%$ \\
& strongly agree & $26.7 \%$ \\
& agree or disagree & $23.3 \%$ \\
& agree & $20 \%$ \\
& strongly agree & $18 \%$ \\
& & $12 \%$ \\
& &
\end{tabular}

According to the survey, we can see that $86.7 \%$ primary school students love English extracurricular activities, but few schools often carry out such activities, and only $30 \%$ of the students believe that they can learn a lot in the English extracurricular activities. Actually, most of the primary school students know little about the hidden curriculum, which is abstract for them. In the survey, we just asked for information about English extracurricular activities that are easier for them to understand. Primary school students love English extracurricular activities, but the English hidden curriculum construction is far from satisfactory, as they could not learn a lot in these activities.

In recent years, many schools have realized the importance of the hidden curriculum and paid more and more attention to the development and utilization of English hidden curriculum. Some primary schools hold English cultural festivals, but the activities are not diversified enough. Many programs or tasks are assigned to classes and students lack initiatives. Few students are really willing to participate in such activities, and their enthusiasm is not fully mobilized. Though the hidden curriculum is not compulsory, the teacher should encourage the students to participate in conductive extracurricular activities. Some schools carry out activities of singing English songs, but the activities fail to effectively integrate language acquisition and music appreciation, fail to use the means of evaluation. The school should take into account of the development needs of all students, the differences between students, and give full play to the role of hidden curriculum, so as to achieve the overall teaching objectives.

\section{Suggestions}

In China, after primary school students have learned English for a period of time, many of them have grasped some English knowledge and can speak a little bit English. How to continue to stimulate and maintain their interest in learning English has become an important task of primary school English teachers. English learning should not be only confined to textbooks and classrooms, and we need to enrich the teaching materials and reform teaching forms, and encourage schools and teachers to change conventional foreign language teaching forms, and develop rich variety of activities, such as English speech and debate, English culture festival (Guo, 
2017), give full play to hidden curriculum, can better improve teaching efficiency and quality. School leaders, teachers, students, families and society should take actions together to promote the construction of English hidden curriculum from different levels, so as to promote the smooth progress of English teaching reform.

\subsection{Highlighting the Characteristics of English Hidden Curriculum on Campus}

The campus education environment is a very important part of the construction of hidden curriculum. The school should try to develop various useful resources to provide students with opportunities to learn and use English (Ministry of education of China, 2011: 42). While constructing primary school hidden curriculum, we should pay attention to the design of school English environment, enriching various teaching resources. In the teaching buildings, schools can set up an English culture corridor and an English corner, so that students can read English aloud or use English to talk freely there in their spare time, and sometimes they can carry out a variety of English extracurricular activities, which are quite essential to improve students' English communicative ability. The bilingual fairy tales, Puss in Boots, Snow White, Ugly Duckling etc., published by FLTRP in China are suitable for the third and fourth-grade students, and this kind of books should be available in the school library. Bookworm series The White Stone, survival game, Robin Hood and other classic simple English and Chinese bilingual reading books, are suitable for primary school senior students to read. Shanghai Foreign Language Education Press in China has also published a series of bilingual English books, very suitable for primary school students to read. The simple bilingual books are helpful for the primary school students to expand their horizons, learn the cultural knowledge of English-speaking countries and improve their intercultural communicative ability. In addition, the school can also make full use of English online resources, and organize various English learning activities to stimulate students' interest in English learning. Well-designed campus environment is a silent language teacher and an important place for English learning.

Carrying out a variety of English extracurricular activities can regulate students' English learning, and stimulate their enthusiasm in reading, speaking and using English. Schools can use English radio to broadcast English news and English songs, and hold the activities, such as English speech competition, English dubbing contest, English singing contest and so on, giving students more opportunities to use English language for interaction, so as to better improve the students' English communicative competence.

\subsection{Integrating English Elements Into Class Culture Construction}

The class culture is also one kind of English hidden curriculum. Effectively integrating English elements with class culture construction can create a good atmosphere of English language and culture learning, which can improve pupils' enthusiasm for English learning. At the primary schools in China, class is the basic unit of the school and essential organizations, and a primary school class generally has a relatively fixed classroom as a place for students to learn. Teachers can organize students to beautify the classroom environment, integrating English language and cultural factors into the classroom layout. For example, we can set up an English learning corner in the teaching building, and paste some posters concerning English language and culture on the walls in the classroom. Celebrated dictums or proverbs, such as "Knowledge is power", "Better early than late", and "Second thoughts are best" become very popular in China's primary schools and they are helpful for students to accumulate English knowledge. Some sentences are profound, thought-provoking, and they are conducive to the formation of primary school students' views on study and life, promoting students' cognitive development. The class can also set up a mobile English book bar, exchanging books with other classes regularly, and students can take turns to borrow English books and newspapers there. Optimizing the classroom English learning environment can create more opportunities for students to communicate with each other in English and help them improve their cross-cultural communicative awareness and ability.

\subsection{Establishing Harmonious Teacher-Student Relationship}

Teachers' emotional attitude and values, ways of thinking and life experience have an important impact on students. In the process of this subtle influence, teachers present as a hidden curriculum (Chen, 2010). Primary school students are willing to take teachers as learning models, for teachers have a great influence on them, and teachers' noble moral sentiment and positive mentality are conducive to promoting primary school students' English acquisition and mental development. English teachers should treat students equally with love, and strive to establish equal and harmonious teacher-student relationship, and create a teacher-student and student-student interactive communication platform for students' use of English. English teachers can also participate in students' English interactive activities, strengthening the interaction between teachers and students, and reducing students' psychological pressure and learning pressure. The flexible and diverse extracurricular activities with the students and teachers' participation and cooperation are helpful for the development of students' English communicative competence and thinking ability. 


\subsection{Constructing Multiple English Hidden Curriculum Resources}

Primary school students like to explore new things, and they are full of curiosity and interest in the new language. They have strong imitation ability and good memory. The participation of community and family in the construction of multiple English hidden curriculum resources is conducive to stimulate primary students' interest in learning English and promote the development of English ability. Communities and families can cooperate to set up community libraries, English classes, English corners, English radio and publicity boards, and make some guideposts and shop signs in English and Chinese. Parents can watch English TV programs, English movies, videos and other audio-visual materials at home with their children, and guide their children to use English online resources. Communities can invite English speaking foreign friends to participate in community language learning activities, such as English corner, English saloon and so on. Teachers and parents should encourage students to participate in community English classes and English corner, communicate with foreign friends in English, so as to better improve students' oral English. Students are encouraged to communicate with foreign netizens and pen PALS through the Internet in English to broaden their horizons, increase their knowledge and improve their intercultural communication skills. Primary school students may be encouraged to take advantage of summer and winter vacations to participate in foreign summer camp activities, experience the culture of English-speaking countries, and better acquire English in the target language environment. In social life, we should strive to provide students with opportunities to use English and deepen their understanding of English language and culture. These experiences are also hidden curriculum resources for their later English acquisition, which can effectively stimulate their intrinsic motivation to learn English and promote the improvement of students' English communication ability.

\section{Concluding Remarks}

China has more than one hundred million primary school students. Some primary schools begin to teach English from Grade one and most schools begin English teaching from Grade three as required by the Ministry of Education of China, and it is improper for all the primary schools to teach English from Grade one, for China's primary school English teaching still faces many challenges and problems in teacher training, teaching materials, teaching objectives and teaching methods etc.. In China, the primary school English curriculum should promote the comprehensive development of learners and cultivating students' comprehensive language application ability (Wang et al., 2012: 18). The hidden curriculum is an important part of elementary school English curriculum system; hidden curriculum and dominant curriculum are not completely separated in education practice, and they are intertwined with each other and work together (Shi, 2010). English teachers at primary schools should make full use of different kinds of hidden curriculum to enrich students' cognitive ways, promoting the all-round development of students. Hidden curriculum construction is beneficial to the primary school English teaching reform, providing a new platform for the students to learn English. Positive hidden curriculum resources are beneficial for the development of primary school students' English communicative competence. It is worth noting that in the implementation of English hidden English curriculum, we should pay attention to teacher training, improvement of teachers' comprehensive quality, and try to improve the teaching conditions, so as to improve teaching quality (Zhou, 2015).

\section{References}

Chen, L. H. (2010). Teacher as curriculum: implication and form. Curriculum, Textbook and Teaching Method, 6.

Cheng, X. T. (2017). English subject core competency and its assessment. China Examinations, 5.

Cheng, X. T., \& Zhao, S. Q. (2016). Essential connotation of English subject core competency. Curriculum, Textbook and Teaching Method, 5.

Guo, B. X., \& Zhang, J. Z. (2017). Cultivation of thinking ability in English subject. Curriculum, Textbook and Teaching Method, 2.

Jackson, P. (1968). Life in Classrooms. New York: Holt, Rinehart, and Winston. https://doi.org/10.1016/ 0024-3205(68)90056-8

Luo, F. J. (2017). Research on the complexity of second language acquisition under the complex theory and its teaching implications. Primary and Secondary School English Teaching and Research, 7.

Ministry of Education of China. (2011). National English Curriculums for compulsory education. Beijing Normal University Press.

Nunan, D. (1989). Hidden agendas: The role of the learner in program implementation. In R. K. Johnson (Ed.), The Second Language Curriculum. Cambridge: Cambridge University Press. 
Shi, F. L. (1996). Curriculum theory - the basis and problems of curriculums. Beijing: Educational Science Press.

Wang, Q. (2012). Practice and exploration of the overall innovation of primary school English curriculum system. Shanghai: Shanghai Education Press.

Ye, L. (2003). National unified examination syllabus for professional master's degree education. Beijing: Beijing Normal University Press.

Yu, B. Y., \& Shi, G. X. (2012). Review and reflection on the hidden curriculum of foreign languages. Computer-assisted Foreign Language Education, 1.

Zhang, H. (2000). Curriculum and teaching theory. Beijing: Educational Science Press.

Zhong, Q. Q. (2009). New curriculum reform opens a new era for curriculum development in China. Chinese Journal of Social Sciences.

Zhou, T. M. (2015). The premise, possibility, and approach of explicit design of hidden curriculum. Science of Education, 1 .

\section{Copyrights}

Copyright for this article is retained by the author(s), with first publication rights granted to the journal.

This is an open-access article distributed under the terms and conditions of the Creative Commons Attribution license (http://creativecommons.org/licenses/by/4.0/). 